\title{
Prevalence and risk factors associated with diabetes retinopathy amongst type II diabetes mellitus at a primary care vision clinic in the eThekwini District, KwaZulu-Natal in 2017
}

\begin{tabular}{|c|c|}
\hline \multicolumn{2}{|c|}{$\begin{array}{l}\text { Authors: } \\
\text { Zaheera Abdool Kader }{ }^{1} \bullet \\
\text { Ozayr Mahomed }\end{array}$} \\
\hline \multicolumn{2}{|c|}{$\begin{array}{l}\text { Affiliations: } \\
{ }^{1} \text { Department of Public Health } \\
\text { Medicine, University of } \\
\text { KwaZulu-Natal, Durban, } \\
\text { South Africa }\end{array}$} \\
\hline \multicolumn{2}{|c|}{$\begin{array}{l}\text { Corresponding author: } \\
\text { Ozayr Mahomed, } \\
\text { mahomedo@ukzn.ac.za }\end{array}$} \\
\hline \multicolumn{2}{|c|}{$\begin{array}{l}\text { Dates: } \\
\text { Received: } 16 \text { Feb. } 2020 \\
\text { Accepted: } 21 \text { May } 2020 \\
\text { Published: } 30 \text { July } 2020\end{array}$} \\
\hline \multicolumn{2}{|c|}{$\begin{array}{l}\text { How to cite this article: } \\
\text { Abdool Kader Z, Mahomed O. } \\
\text { Prevalence and risk factors } \\
\text { associated with diabetes } \\
\text { retinopathy amongst type } \\
\text { II diabetes mellitus at a } \\
\text { primary care vision clinic in } \\
\text { the eThekwini District, } \\
\text { KwaZulu-Natal in 2017. } \\
\text { Afr Vision Eye Health. } \\
\text { 2020;79(1), a556. https://doi. } \\
\text { org/10.4102/aveh.v79i1.556 }\end{array}$} \\
\hline \multicolumn{2}{|c|}{$\begin{array}{l}\text { Copyright: } \\
\text { (C) 2020. The Author(s } \\
\text { Licensee: AOSIS. This } \\
\text { is licensed under the } \\
\text { Creative Commons } \\
\text { Attribution License. }\end{array}$} \\
\hline \multicolumn{2}{|l|}{ Read online: } \\
\hline 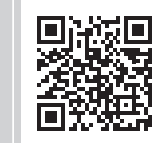 & $\begin{array}{l}\text { Scan this QR } \\
\text { code with your } \\
\text { smart phone or } \\
\text { mobile device } \\
\text { to read online. }\end{array}$ \\
\hline
\end{tabular}

Background: Diabetic retinopathy (DR) is the fourth leading cause of blindness and is a major contributor to visual impairment after cataract, glaucoma and age-related macular degeneration. Globally, 55\% of patients with diabetes are likely to suffer from DR.

Aim: To determine the prevalence and risk factors associated with DR amongst type II diabetic patients.

Setting: The study was conducted at a non-governmental eye clinic between March and December 2017 in the eThekwini district of KwaZulu-Natal.

Methods: Patients' demographic and clinical data were obtained through randomised systematic sampling from the medical records of 298 patients. Univariate analysis followed by multivariate logistical analysis was used to test the associations.

Results: In all, $42 \%$ of the sampled patients had DR, with $98 \%$ (122 patients) displaying DR in both eyes. The mean age of DR patients was 64 years (standard deviation [SD]: 9.34), with a female $(n=97)$ predominance. Patients with diabetes for $>10$ years (odds ratio [OR]: $2.53 ; 95 \%$ confidence interval [CI]: 1.39-4.62), comorbidity with hypertension (OR: 7.43; 95\% CI: 1.57-35.28), and presence of cardiovascular diseases (OR: 4.3; 95\% CI: 2.49-7.44) were significant risk factors for DR, whilst an elevated cholesterol level showed an increased but non-significant risk.

Conclusion: Diabetic retinopathy was higher in this study than the global estimated prevalence. Lifestyle diseases and its associated modifiable risk factors are important contributors to the development of DR. A holistic approach towards diabetes, which includes primary prevention and aggressive management and control of hypertension, diabetes, elevated cholesterol, and cardiovascular diseases, is required to reduce the incidence of diabetes retinopathy.

Keywords: diabetes; retinopathy; primary care; comorbidity; modifiable risk factors.

\section{Introduction}

Over the past 25 years, the prevalence of diabetes has increased globally with an estimated 415 million people living with it in 2015. ${ }^{1}$ In 2019, approximately 463 million people (20-79 years) were living with diabetes globally, and this number is expected to increase to 700 million by the year $2045 .^{2}$ Almost $79 \%$ people having diabetes live in low-income and middle-income countries, with $77 \%$ of deaths in Africa because of diabetes occurring in individuals aged less than 60 years. $^{2}$

Estimates from the International Diabetes Federation have indicated that in South Africa, 3.5 million people aged between 20 and 79 years were diagnosed with diabetes equalling almost $7 \%$ of the population, ${ }^{1}$ with this number increasing to 4.5 million people in $2019 .{ }^{2}$

The impact of diabetes on the health services is not only because of the high burden of diabetic patients but also because of the increasing complications associated with poor blood glucose control. Poor blood glucose control is associated with long-term complications because of damage, dysfunction and failure of different organs. The major long-term complications associated with diabetes are macrovascular (peripheral arterial disease, stroke and coronary artery disease) and microvascular (retinopathy, neuropathy and nephropathy. ${ }^{3}$ 
Diabetic retinopathy (DR) is the most common microvascular complication found in diabetics that has the potential to cause loss of vision. Globally, 55\% of diabetics are likely to suffer from DR. ${ }^{4}$ In South Africa, the prevalence of DR was estimated to be between $5 \%$ and $10 \%{ }^{5}$ and is the fourth leading cause of blindness after cataract, glaucoma and agerelated macular degeneration. ${ }^{6}$ In addition, DR is the major contributor to visual impairment after refractive errors, cataract and glaucoma. ${ }^{6}$

Patients with DR are classified as early phase nonproliferative DR (NPDR) and late phase proliferative DR (PDR) patients. ${ }^{7}$ Clinically, the first retinal manifestations are small micro-aneurysms, followed by hard exudates, dot and blot haemorrhages, leading to visual impairment and blindness ultimately.

Diabetic retinopathy has serious consequences for both the patient and health system. The disease decreases the quality of life of affected individuals. Daily activities such as watching television, reading, driving, walking and recognising faces are affected. This loss of vision can also lead to depression, decreased mobility and eventual blindness. As the disease worsens, the economic burden of being diabetic with DR aggravates. Diabetic retinopathy has both direct (medical and non-medical) and indirect expenditures. ${ }^{8}$ Ocular medications, retinal-fundus photography, visits to optometrists and ophthalmologists and procedures related to DR are examples of direct medical expenditures. Non-direct medical expenditures include transportation expenses, loss of employment, loss of productivity and early retirement.

Diabetic retinopathy is preventable and treatable if patients with diabetes are identified and diagnosed early and are managed appropriately by the provision of comprehensive patient-centred care and provided with ongoing selfmanagement education.

\section{Aim and objectives}

The aim of this study was to determine the prevalence and risk factors associated with DR in adult patients (aged $>25$ years) with type II diabetes mellitus at a nongovernmental vision clinic in the eThekwini district of KwaZulu-Natal, South Africa, between March and December 2017. Following are the specific objectives of the study:

- To determine the prevalence of DR;

- To determine the risk factors associated with DR in adult patients (aged $>25$ years) with type II diabetes mellitus.

\section{Research methods and design Study design}

A retrospective analytical cross-sectional study design was used.

\section{Setting}

The study was conducted at Vision 4 Life clinic managed by a humanitarian organisation, the Alimdaad Foundation, a non-profit organisation. Vision 4 Life clinic is situated in a popular suburb called Sherwood, which is easily accessible by private and public transport and caters all patients (urban and rural). The Vision 4 Life clinic's aim is to help underprivileged people that cannot afford private eye care. The clinic helps with the backlog from public health sector. The clinic has a full-time voluntary optometrist, directly involved in working to meet the comprehensive eyecare needs of the patients. The support team consists of an Islamic priest, a project manager and an administrator. The working hours are from 08:00 to 17:00, Monday to Friday, and diabetic patients are seen and reviewed for DR on daily basis.

\section{Study population and sampling strategy}

The study population included all non-insulin-dependent diabetic patients aged more than 25 years, attending Vision 4 Life clinic, and had been on diabetes treatment between 01 March 2017 and 31 December 2017. A sample size of 385 patients was calculated based on $95 \%$ confidence interval (CI), with a relative precision of $5 \%$, power $80 \%$ and $e$ (margin of error $)=5 \%$. Randomised systematic sampling was used. A random starting point was selected based on a random sampling table. Thereafter, every 10th patient was selected and the records were retrieved.

\section{Data collection}

Diabetic retinopathy was assessed using a Canon ${ }^{\circledR}$ nonmydriatic digital fundus camera by an optometrist. The fundus photographs taken were stored as JPEG files in a computer. The DR grading and classification used by optometrists are based on the Ophthalmological Society of South Africa (OSSA) DR screening system guidelines. ${ }^{9}$ Diabetic retinopathy is classified as (1) no DR, (2) mild NPDR, (3) moderate NPDR, and (4) PDR. ${ }^{9}$

Patient records were retrieved from the medical registry and the researcher reviewed all details and completed the data extraction sheet with the following information: Age, gender, ethnicity, duration of living with diabetes, consumption of alcohol, use of tobacco products, body mass index (BMI), whether the patient was on medication for hypertension, presence of cardiovascular diseases, cholesterol level, and the last glycated haemoglobin $(\mathrm{HbA} 1 \mathrm{c})$ level. The research team comprised two data collection personnel, that is, the principal researcher and one research assistant who extracted clinical information to determine risk factors of DR amongst type II diabetics.

\section{Data management and analysis}

Data were extracted from paper-based records using a data collection tool, and the information was transferred to Microsoft Excel. The data were exported to Software for Statistics and Data Science for Analysis (STATA, version 13). 
The prevalence and baseline characteristics of all participants were analysed descriptively. Bivariate analysis followed by logistical regression was used to test for associations between dependent and independent variables. Results were considered significant at $p<0.05$.

\section{Ethical considerations}

Ethical approval was obtained from the Biomedical Research and Ethics Committee (BREC) of the University of KwaZuluNatal (approval number: BE097/18).

\section{Results}

A total of 298 patients who had been on diabetes treatment between 01 March 2017 and 31 December 2017 and fulfilled the inclusion criteria of type II diabetes, aged more than 25 years, and whose records were retrievable, were included in the study.

\section{Prevalence of diabetic retinopathy}

In all, $42 \%(n=125)$ of the sampled patients displayed signs of progressive DR, with $98 \%(n=122)$ of the sampled patients displaying DR in both eyes (Figure 1).

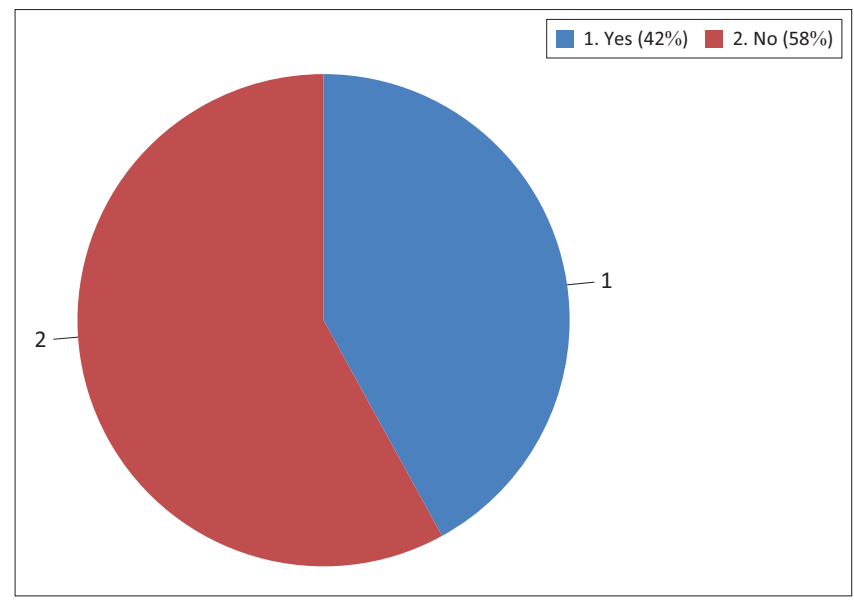

FIGURE 1: Pie graph representing proportion of sampled patients diagnosed with progressive diabetic retinopathy $(42 \%)$ at the Vision 4 Life clinic, eThekwini, between March and December 2017.

\section{Socio-demographic profile of study population}

In the sampled patients, $226(75.84 \%)$ were females, with a female to male ratio of $3: 1 ; 79 \%(n=235)$ patients were Indians, $11 \%(n=34)$ were mixed race and $10 \%$ $(n=29)$ were black Africans. The mean age of the study population was 64 years (standard deviation [SD]: 10.35). Of the 298 patients, 184 (62\%) were diabetic for less than 10 years.

The mean age of DR patients was 64 years (SD: 9.34, ranging between 39 and 88 years) with a median age of 64 years (interquartile range [IQR]: 57-70). More females $(n=97)$ than males $(n=28)$ had DR. The majority of the patients with DR were of Indian descent $(n=101)$, followed by mixed race $(n=14)$ and black race $(n=10)$ groups (Table 1$)$. The study had 101 patients $(82 \%)$ with DR who had been diabetic for more than 10 years.

\section{Modifiable and clinical risk factors amongst study population}

Major risk factors present in both study population and patients with DR in particular included high cholesterol levels (> $6 \mathrm{mmol} / \mathrm{L})$, hypertension and BMI $>30 \mathrm{~kg} / \mathrm{m}^{2}$. In addition, $71 \%(n=88)$ patients with DR had concurrent cardiovascular diseases excluding hypertension (Table 2). It was difficult to assess blood glucose control in the sampled patients as only four (1.34\%) attending the clinic had an $\mathrm{HbA} 1 \mathrm{c}$ test completed.

\section{Association between socio-demographic factors and diabetic retinopathy}

Bivariate analysis indicated a non-significant increased odds for DR amongst patients aged > 60 years (odds ratio [OR]: 1.06; 95\% CI: 0.62-1.79); females (OR: 1.18; 95\% CI: 0.66-2.12), Indian and mixed ethnicity (OR: 1.42; 95\% CI: 0.60-3.55); and BMI > $30 \mathrm{~kg} / \mathrm{m}^{2}$ (OR: 1.79; 95\% CI: 0.90-3.73). Smoking (OR: 1.69; 95\% CI: 0.98-2.90) showed a significant increased odds for DR on bivariate analysis but was non-significant after multivariate

TABLE 1: Distribution of age, gender, ethnicity and duration of diabetes of the sampled study population and diabetic retinopathy patients consulted at the Vision 4 Life clinic, eThekwini, between March and December 2017.

\begin{tabular}{|c|c|c|c|c|c|c|c|c|c|c|c|c|c|}
\hline \multirow[t]{2}{*}{ Variables } & \multicolumn{4}{|c|}{ Study population } & \multicolumn{4}{|c|}{ Patients with DR $(n=125)$} & \multicolumn{4}{|c|}{ Non-DR patients $(n=173)$} & \multirow[t]{2}{*}{$p$} \\
\hline & $n$ & $\%$ & SD & IQR & $n$ & $\%$ & SD & IQR & $n$ & $\%$ & SD & IQR & \\
\hline \multicolumn{14}{|l|}{ Age } \\
\hline Mean & 64 & - & 10.35 & - & 64 & - & 9.34 & - & 64 & - & 11.06 & - & - \\
\hline Median & 64 & - & - & $58-71$ & 64 & - & - & $57-70$ & 65 & - & - & $58-72$ & \\
\hline \multicolumn{14}{|l|}{ Gender } \\
\hline Female & 226 & 76 & - & - & 97 & 78 & - & - & 129 & 75 & - & - & 0.546 \\
\hline \multicolumn{14}{|l|}{ Ethnicity } \\
\hline Indian and mixed race & 269 & 90 & - & - & 115 & 92 & - & - & 154 & 89 & - & - & 0.391 \\
\hline African & 29 & 10 & - & - & 10 & 8 & - & - & 19 & 11 & - & - & \\
\hline \multicolumn{14}{|l|}{ Duration of diabetes } \\
\hline$<10$ years & 114 & 38 & - & - & 24 & 12 & - & - & 90 & 52 & - & - & $<0.001$ \\
\hline$>10$ years & 184 & 62 & - & - & 101 & 82 & - & - & 83 & 48 & - & - & \\
\hline
\end{tabular}

DR, diabetic retinopathy; SD, standard deviation; IQR, interquartile range. 
analysis. Patients with diabetes for more than 10 years had a significantly increased odds for DR after bivariate (OR: 4.56; 95\% CI: 2.60-8.15) and multivariate analysis (OR: 2.53; $95 \%$ CI: $1.39-4.62)$.

Comorbidity with hypertension (OR: 13.42; 95\% CI: $3.28-117.38$ ), presence of cardiovascular diseases (OR: 6.38; 95\% CI: 3.72-10.97) and high cholesterol level (OR: 9.59; 95\% CI: 2.88-49.77) showed significantly increased odds for DR after bivariate analysis. After multivariate analysis, hypertension (OR: 7.43; 95\% CI: 1.57-35.28) and presence of cardiovascular diseases (OR: 4.3 ; 95\% CI: 2.49-7.44) remained statistically significant risk factors for the development of DR (Table 3). Increased cholesterol (OR: 2.83 ; 95\% CI: 0.75-0.64) was not significant after multivariate analysis.

\section{Discussion}

The prevalence of DR (42\%) is similar to another local study conducted in 2014 at a quaternary hospital in Durban that showed a DR prevalence of $39 \%{ }^{10}$ However, the findings are higher than the results of a previous study conducted at a diabetic clinic of a hospital in South Africa that showed a prevalence of $22.8 \%$ amongst type II diabetics. ${ }^{11}$ In addition, the findings are higher than two other global studies - the first being a study from Saudi Arabia conducted in 2016 that reported a DR prevalence of $36.4 \%,{ }^{12}$ and the second one from India performed in 2017 with a DR prevalence of $32.5 \%{ }^{13}$ The gender distribution of DR in our study $(97 / 125)$ is similar to the previous study conducted in Johannesburg that showed a greater occurrence of DR in females. ${ }^{11}$ In addition, our findings

TABLE 2: Frequency table of the clinical profile of study population and diabetic retinopathy patients.

\begin{tabular}{|c|c|c|c|c|c|c|c|}
\hline \multirow[t]{2}{*}{ Variables } & \multicolumn{2}{|c|}{ Study population } & \multicolumn{2}{|c|}{ Patients with DR $(n=125)$} & \multicolumn{2}{|c|}{ Non-DR patients $(n=173)$} & \multirow[t]{2}{*}{$p$} \\
\hline & $n$ & $\%$ & $n$ & $\%$ & $n$ & $\%$ & \\
\hline Consumes alcohol & & & & & & & 0.796 \\
\hline Yes & 8 & 3 & 3 & 2 & 5 & 3 & \\
\hline No & 290 & 97 & 122 & 98 & 168 & 97 & \\
\hline Current/history of smoking & & & & & & & 0.04 \\
\hline Yes & 84 & 28 & 43 & 34 & 41 & 24 & \\
\hline No & 214 & 72 & 82 & 66 & 132 & 76 & \\
\hline Presence of cardiovascular diseases & & & & & & & $<0.001$ \\
\hline Yes & 135 & 45 & 88 & 71 & 47 & 27 & \\
\hline No & 163 & 55 & 37 & 29 & 126 & 73 & \\
\hline High cholesterol levels (> $5 \mathrm{mmol} / \mathrm{L}$ ) & & & & & & & $<0.001$ \\
\hline Yes & 262 & 88 & 122 & 98 & 140 & 81 & \\
\hline No & 36 & 12 & 3 & 2 & 33 & 19 & \\
\hline Hypertension & & & & & & & $<0.001$ \\
\hline No & 33 & 11 & 2 & 2 & 31 & 18 & \\
\hline HbA1c level measured & & & & & & & 0.02 \\
\hline Yes & 4 & 1 & 4 & 3 & 0 & & \\
\hline No & 294 & 99 & 121 & 97 & 173 & 100 & \\
\hline Body mass index (BMI) & & & & & & & 0.08 \\
\hline$>30 \mathrm{~kg} / \mathrm{m}^{2}$ & 249 & 84 & 110 & 88 & 139 & 80 & \\
\hline$<30 \mathrm{~kg} / \mathrm{m}^{2}$ & 49 & 16 & 15 & 12 & 34 & 20 & \\
\hline
\end{tabular}

$\mathrm{DR}$, diabetic retinopathy; HbA1c, glycated haemoglobin level.

TABLE 3: Bivariate and multivariate analysis of patient's socio-demographic and clinical factors associated with diabetic retinopathy.

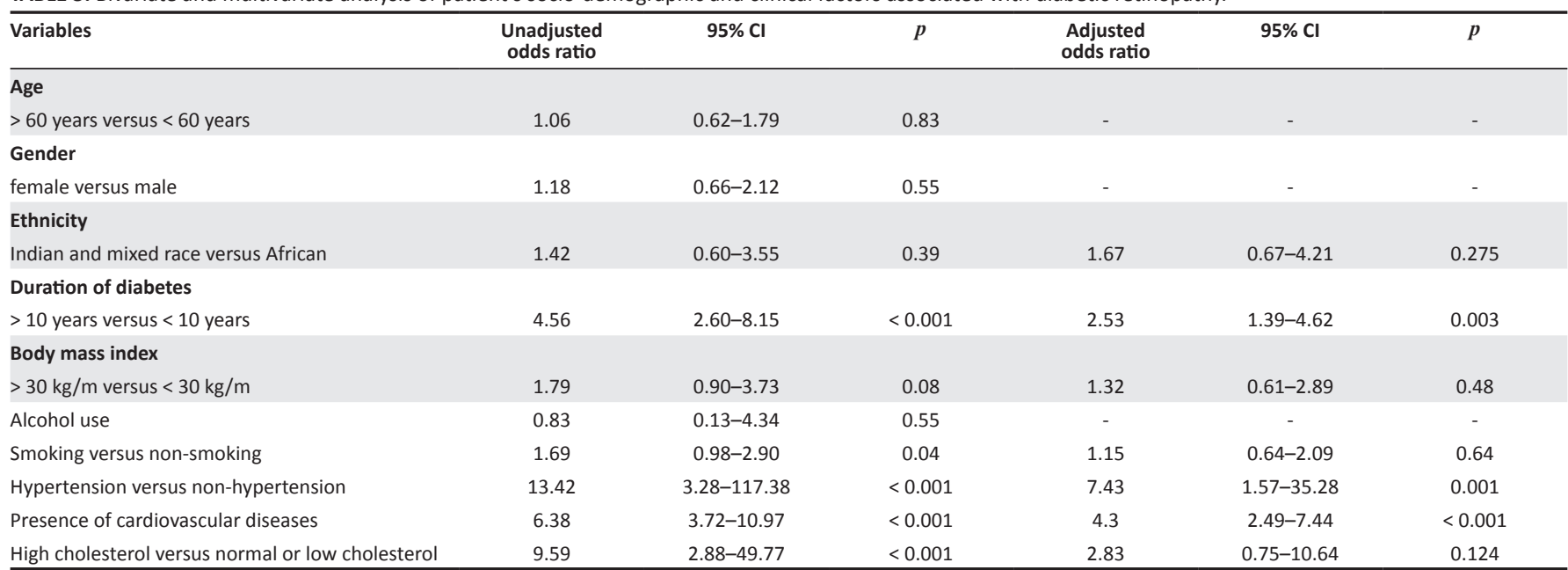

$\mathrm{Cl}$, confidence interval. 
showed a higher prevalence of DR amongst patients of Indian and mixed descent (42\%) versus African patients $(35 \%)$ as well as an increased but non-significant risk of DR amongst Indian and mixed descent compared to African patients (adjusted OR [AOR]: 1.67; 95\% CI: 0.67-4.21). Another study conducted at a specialist diabetic clinic of a Johannesburg hospital found that DR prevalence was significantly less in Africans than in whites and Indians. ${ }^{14}$ However, other studies have reported similar prevalence of DR in Africans, whites and Indians. ${ }^{15}$

A possible explanation for the findings in the current study is that although alcohol consumption and smoking were low, prevalence of high BMI (84\%), high cholesterol levels (88\%), co-morbid hypertension (89\%) and poor management of diabetes (low completion of Hb1AC levels) demonstrated a high-risk population of diabetes-related complications.

This study shows three factors that are significantly associated with the development of DR, namely concomitant hypertension, cardiovascular diseases and $>10$-year duration of diabetes. Prevalence of type 2 diabetes for more than 10 years was statistically significant in associating with DR (OR: 2.53; 95\% CI: 1.39-4.62). Similar findings have been noted in other research studies as well. ${ }^{16,17,18}$ The pathogenesis of microvascular complications could be because of the magnitude and/or prolonged exposure to hyperglycaemia either independently or in combination with other risk factors. ${ }^{18}$

Although not statistically significant, our findings of patients aged $>60$ years being at an increased odds (OR: 1.06) of developing DR are consistent with studies conducted in Ethiopia ${ }^{16}$ and United Arab Emirates. ${ }^{17}$ Age as a risk factor for developing DR is related with the duration of diabetes.

There are contradictory findings with respect to association between gender and DR. Our study showed females to be at non-significant increased odds of developing DR as compared to males. However, a study from Singapore showed that females were at a significantly increased odds of developing DR. ${ }^{19}$ A number of studies have shown findings to the contrary, indicating that females have significantly less DR than males. ${ }^{20}$

A number of epidemiological studies conducted to determine the association between obesity and DR have shown inconsistent results. A meta-analysis using the Cochrane Library, PubMed, and Embase databases up to December 2016 for articles evaluating the effects of BMI on DR in patients with type 1 or type 2 diabetes indicated that neither overweight nor obesity conferred an increased risk of DR. ${ }^{21}$ The findings from our study indicate a non-significant increased odds for DR in obese patients (BMI $>30 \mathrm{~kg} / \mathrm{m}^{2}$ ) compared with normal or overweight diabetic patients.

Comorbidity with hypertension was shown to be a highly significant risk factor amongst DR patients in our study.
This finding is consistent with a number of studies demonstrating a positive link between hypertension and DR amongst type II diabetic patients. ${ }^{16,22}$ Hypertension has an exponential impact on poor vascular outcomes (including DR) amongst diabetic patients. ${ }^{23}$ There are two pathophysiological mechanisms by which hypertension increases the risk of or exacerbates DR. Endothelial dysfunction caused by higher viscosity of blood because of the mechanical stretch and sheer stress imparted on endothelial cells owing to increased perfusion of the retina. ${ }^{19}$ In addition, angiotensin II, responsible for blood pressure regulation, may activate protein kinase $C$ that triggers a cascade reaction causing endothelial damage as well as increased activation and adhesion of leukocytes in the retina. ${ }^{24}$

The patients with DR in our study population demonstrated a high prevalence of elevated cholesterol levels (98\%) and comorbid cardiovascular diseases $(88 \%)$; these were positive predictors of DR as demonstrated by the increased odds ratio. Association between elevated cholesterol levels and DR is inconsistent. ${ }^{25}$

\section{Limitations of the study}

Although meticulousness and diligence were maintained to ensure integrity and veracity of the study, it had a number of limitations. This study was a retrospective study that was dependent on previously captured information; the study remained vulnerable to information bias because of limited and missing information from record cards that resulted in not meeting its target sample size. This study was conducted at a single eye clinic, and there is a possibility of selection bias as the patients were referred from low socio-economic old age homes, rural settings and hospice/frail care centres.

\section{Conclusion}

Diabetic retinopathy was higher (42\%) in this study than the global estimated prevalence of $34.6 \%$. Three factors are significantly associated with the development of DR, namely concomitant hypertension, elevated cholesterol level and cardiovascular diseases, and > 10-year duration of diabetes. A holistic approach towards the management of diabetes, which includes primary prevention that addresses the modifiable risk factors, and secondary prevention in the form of aggressive management of hypertension, diabetes, elevated cholesterol and cardiovascular diseases, will assist in reducing the incidence of DR. All diabetic patients should receive annual ophthalmic examination to identify early retinal changes to facilitate early referral to tertiary centres.

\section{Acknowledgements}

The authors wish to acknowledge the Al-Imdaad Foundation for granting permission to use their facility for the research. 


\section{Competing interests}

The authors declare that they have no financial or personal relationships that may have inappropriately influenced them in writing this article.

\section{Authors' contributions}

Z.A.K. conducted the research at the hospital and contributed to the first draft. O.M. analysed the results and developed the manuscript.

\section{Funding information}

This study was self-funded by the authors.

\section{Data availability statement}

Data are available from the corresponding author upon reasonable request.

\section{Disclaimer}

The views and opinions expressed in the submitted article are those of the authors and do not necessarily reflect the official policy or position of any affiliated agency of the authors.

\section{References}

1. International Diabetes Federation. IDF diabetes atlas. 7th ed. Brussels: International Diabetes Federation; 2015.

2. International Diabetes Federation. IDF diabetes atlas. 9th ed. Brussels: International Diabetes Federation; 2019.

3. Fowler MJ. Microvascular and macrovascular complications of diabetes. Clin Diabetes. 2008;26(2):77-82. https://doi.org/10.2337/diaclin.26.2.77

4. Hofman KJ, Cook C, Levitt N. Preventing diabetic blindness: A priority for South Africa. S Afr Med J. 2014;104(10):661-662. https://doi.org/10.7196/SAMJ.8580

5. Levy J, Jotkowitz AB. Diabetes in Africa: Screening for diabetic retinopathy. Eur J Intern Med. 2010;21(3):145-146. https://doi.org/10.1016/j.ejim.2010.02.010

6. Cockburn N, Steven D, Lecuona K, et al. Prevalence, causes and socio-economic determinants of vision loss in Cape Town, South Africa. PLoS One. 2012;7(2):e30718. https://doi.org/10.1371/journal.pone.0030718

7. Yau JW, Rogers SL, Kawasaki R, et al. Global prevalence and major risk factors of diabetic retinopathy. Diabetes Care. 2012;35(3):556-564. https://doi.org/ $10.2337 / \mathrm{dc} 11-1909$
8. Erasmus RT, Soita DJ, Hassan MS, et al. High prevalence of diabetes mellitus and metabolic syndrome in a South African coloured population: Baseline data of a study in Bellville, Cape Town. S Afr Med J. 2012;102(11 Pt 1):841-844. https://doi. org/10.7196/SAMJ.5670

9. Cook S. Diabetic retinopathy - The Ophthalmology Society of Southern Africa screening programme. S Afr Med J. 2013;103(7):449-451. https://doi.org/ 10.7196/SAMJ.7136

10. Pirie FJ, Maharaj S, Esterhuizen TM, et al. Retinopathy in subjects with type 2 diabetes at a tertiary diabetes clinic in Durban, South Africa: Clinical, biochemical and genetic factors. J Clin Transl Endocrinol. 2014; 1(1): e9-e12. https://doi. org/10.1016/j.jcte.2013.12.002

11. Sukha A, Rubin A. Demographic, medical and visual aspects of diabetic retinopathy (DR) and diabetic macular edema (DME) in South African diabetic patients. Afr Vis Eye Health. 2009;68(2):a157. https://doi.org/10.4102/aveh.v68i2.157

12. Ahmed RA, Khalil SN, Al-Qahtani MA. Diabetic retinopathy and the associated risk factors in diabetes type 2 patients in Abha, Saudi Arabia. J Family Community Med. 2016;23(1):18-24. https://doi.org/10.4103/2230-8229.172225

13. Nadarajan B, Saya GK, Krishna RB, et al. Prevalence of diabetic retinopathy and its associated factors in a rural area of Villupuram district of Tamil Nadu, India. J Clin Diagn Res. 2017;11(7):LC23-LC26. https://doi.org/10.7860/JCDR/2017/20946.10294

14. Carmichael TR, Carp GI, Welsh ND, et al. Effective and accurate screening for diabetic retinopathy using a 60 degree mydriatic fundus camera. S Afr Med J. 2005;95(1):57-61. https://doi.org/10.1080/22201009.2005.10872109

15. Kalk WJ, Joannou J, Ntsepo S, et al. Ethnic differences in the clinical and laboratory associations with retinopathy in adult onset diabetes: Studies in patients of African, European and Indian origins. J Intern Med. 1997;241(1):31-37. https:// doi.org/10.1046/j.1365-2796.1997.70892000.x

16. Worku D, Hamza L, Woldemichael K. Patterns of diabetic complications at Jimma University specialized hospital, southwest Ethiopia. Ethiop J Health Sci. 2010;20(1):33-39. https://doi.org/10.4314/ejhs.v20i1.69424

17. Jelinek HF, Osman WM, Khandoker AH, et al. Clinical profiles, comorbidities and complications of type 2 diabetes mellitus in patients from United Arab Emirates. BMJ Open Diabetes Res Care. 2017;5(1):e000427. https://doi.org/10.1136/ bmjdrc-2017-000427

18. Niazi M, Akram A, Naz M, et al. Duration of diabetes as a significant factor for retinopathy. Pak J Opthalmol. 2010;26:182-186.

19. Tarr JM, Kaul K, Chopra M, et al. Pathophysiology of diabetic retinopathy. ISRN Ophthal. 2013;2013:343560. https://doi.org/10.1155/2013/343560

20. Cherchi S, Gigante A, Contini $P$, et al. Male type 2 diabetic patients have higher diabetic retinopathy prevalence. Diabetes. 2018;67:599. Supplement. https://doi org/10.2337/db18-599-P

21. Zhou $Y$, Zhang $Y$, Shi $K$, et al. Body mass index and risk of diabetic retinopathy: $A$ meta-analysis and systematic review. Medicine (Baltimore). 2017;96(22):e6754 https://doi.org/10.1097/MD.0000000000006754

22. Shah K, Gandhi A, Natarajan S. Diabetic retinopathy awareness and associations with multiple comorbidities: Insights from DIAMOND study Indian I Endocrinol Metab. 2018;22(1): 30-35. https://doi.org/10.4103/ijem.IJEM_240_17

23. Giunti S, Barit D,Cooper ME. Mechanisms of diabetic nephropathy: Role of hypertension. Hypertension. 2006;48(4):519-526. https://doi.org/10.1161/01. HYP.0000240331.32352.0c

24. Aiello LP, Bursell SE, Clermont A, et al. Vascular endothelial growth factor-induced retinal permeability is mediated by protein kinase $C$ in vivo and suppressed by an orally effective beta-isoform-selective inhibitor. Diabetes. 1997;46(9):1473-1480. https://doi.org/10.2337/diab.46.9.1473

25. Yue Zhou M, Changyun W, Shi K, et al. Relationship between dyslipidemia and diabetic retinopathy: A systematic review and meta-analysis. Medicine (Baltimore) 2018;97(36):e12283. https://doi.org/10.1097/MD.0000000000012283 